\title{
ANÁLISE DE AGRESSIVIDADE E INCRUSTAÇÃO DAS ÁGUAS SUBTERRÂNEAS NA REGIÃO URBANA DE CAMPO GRANDE - MS
}

\author{
ANALYSIS OF AGGRESSIVITY AND ENCRUSTATION OF \\ GROUNDWATER IN THE URBAN AREA OF CAMPO GRANDE - MS
}

\author{
Guilherme Henrique Cavazzana ${ }^{1}$, Giancarlo Lastoria ${ }^{1}$, Sandra Garcia Gabas ${ }^{1}$, Clayton \\ Marcos Pereira Bezerra ${ }^{2}$
}

Artigo recebido em: 19/03/2012 e aceito para publicação em: 22/05/2012

\begin{abstract}
Campo Grande city, the capital of Mato Grosso do Sul State, has 40\% of its water supply from groundwater system, mainly from Serra Geral Aquifer, but also from Guarani Aquifer and Bauru Aquifer System. The lack of detailed knowledge of the hydrogeology, including hydrochemistry characterizations, has caused loss of wells due to pipe disruption and consequently the decrease of well production. This study aimed at determining the groundwater corrosion potential, as well as the spatial distribution of this parameter in the basalts of Serra Geral Aquifer System in the urban area of Campo Grande. The Langelier Saturation Index (LSI) and Ryznar Stability Index (RSI) have been determined and they indicate that the groundwater has corrosive behavior. According to LSI index, $64 \%$ of groundwater are classified as low aggressivity, diminishing from northeast to southwest direction of the studied area, following the pattern of $\mathrm{pH}$ values and groundwater's flow direction. The spatial distribution of this variable can help the management of the water supply system, especially in the specification and maintenance of equipment used in wells.
\end{abstract}

Keywords: Langelier Saturation Index. Ryznar Stability Index. Serra Geral Aquifer System. Campo Grande - MS.

Resumo: Em Campo Grande, capital do Estado de Mato Grosso do Sul, 40\% do sistema de abastecimento de água é suprido pelo manancial subterrâneo, com maior participação do Sistema Aquífero Serra Geral, em relação aos Sistemas Aquíferos Bauru e Guarani. A falta de conhecimentos detalhados da hidrogeologia, sobretudo a caracterização hidroquímica, vem causando perda de poços devido ao rompimento da tubulação, com consequente diminuição de sua produção. Este trabalho visou determinar o potencial de incrustação ou corrosão da água subterrânea, bem como a distribuição espacial destes parâmetros no Aquífero Serra Geral, na região urbana da cidade, aplicando-se os Índices de Saturação de Langelier (LSI) e de Estabilidade de Ryznar (RSI). Constatou-se que as águas subterrâneas explotadas neste Aquífero têm comportamento corrosivo, sendo 64\% classificadas como corrosão leve, pelo índice LSI, com sentido predominante NE-SW de diminuição da agressividade, seguindo o incremento dos valores de $\mathrm{pH}$ na direção do fluxo. A distribuição espacial desta variável pode auxiliar no gerenciamento do sistema de abastecimento de água, principalmente na especificação e manutenção dos equipamentos de captação empregados nos poços tubulares.

Palavras Chave: Índice de Saturação de Langelier. Índice de Estabilidade de Ryznar. Sistema Aquífero Serra Geral, Campo Grande - MS.

\section{INTRODUÇÃO}

Uma das alternativas para atender o consumo humano provém das águas subterrâneas que são relativamente menos susceptíveis aos poluentes antrópicos e possuem melhor qualidade, devido ser, na grande maioria, originárias de águas de chuvas, que se infiltram nos solos e rochas, até atingirem um aquífero poroso ou fissural e ficarem disponíveis para serem explotadas.

Tal alternativa vem sendo amplamente utilizada no Brasil desde a década de 60 , quando os estudos com este enfoque prosperaram, inicialmente na região nordeste (FEITOSA, 2008), tendo ocorrido a intensificação do uso dos recursos hídricos subterrâneos em áreas urbanas brasileiras nos últimos vinte anos, característica esta compartilhada por alguns países em desenvolvimento (FOSTER et al., 2011).

Na cidade de Campo Grande-MS não é diferente: as águas subterrâneas são utilizadas como complemento para o sistema de abastecimento, principalmente pela baixa densidade de corpos hídricos superficiais com vazão e qualidade suficientes para

\footnotetext{
${ }^{1}$ UFMS/CCET, Brasil (gui_cavazzana@yahoo.com.br, g.lastoria@ufms.br, sandra.gabas@ufms.br)

2 Águas Guariroba S/A, Brasil (clayton.bezerra@aguasguariroba.com.br)
} 
atender as demandas. O Córrego Guariroba é o principal manancial de abastecimento, cuja distância de $30 \mathrm{~km}$ do centro consumidor impõe custos elevados de energia para o seu recalque até a estação de tratamento e distribuição.

Segundo o Plano Estadual dos Recursos Hídricos de Mato Grosso do Sul (SEMAC, 2010), os habitantes da cidade de Campo Grande - MS consomem diariamente cerca de $212.200 \mathrm{~m}^{3}$ de água proveniente da Unidade de Planejamento e Gerenciamento - UPG Rio Pardo. Deste total, 60\% é suprido pelos mananciais de águas superficiais, captações dos Córregos Guariroba, Lajeado e Desbarrancado; e os outros $40 \%$ são complementados pelas águas subterrâneas dos Sistemas Aquíferos Serra Geral, Guarani e Bauru, em ordem de explotação.

O maior problema enfrentado para a captação de águas subterrâneas advém da falta de conhecimentos básicos sobre as suas formas de ocorrência e circulação, seus aspectos hidrogeológicos, legais, além da falta de controle e de fiscalização das condições de uso e de proteção deste manancial (GONÇALES e GIAMPÁ, 2006).

Muitas vezes, a capacidade de corrosão e in- crustação da água explorada não é considerada; podendo ocorrer perdas de investimento devido ao rompimento da tubulação (do poço e/ou da motobomba) ou a diminuição de sua vazão devido às incrustações, necessitando manutenções com maior frequência para reparo e substituição de equipamentos ou até mesmo a inutilização do poço.

\section{OBJETIVO}

Este trabalho teve por objetivo caracterizar a hidroquímica do Sistema Aquífero Serra Geral SASG, em relação ao seu potencial de incrustação ou corrosão, bem como a distribuição espacial destas variáveis na região urbana de Campo Grande - MS.

\section{ÁREA DE ESTUDO}

A área de pesquisa abrange a região urbana de Campo Grande-MS, localizada na região CentroOeste do Brasil, no centro do Estado de Mato Grosso do Sul. O município possui área total de 8.096 $\mathrm{km}^{2}$; desses $353 \mathrm{~km}^{2}$ correspondem à região urbana ( Figura 1), delimitada pela Lei Complementar $\mathrm{N}^{\circ}$ 74/2005 (CAMPO GRANDE, 2005), com $787 \mathrm{mil}$ habitantes (IBGE, 2010).

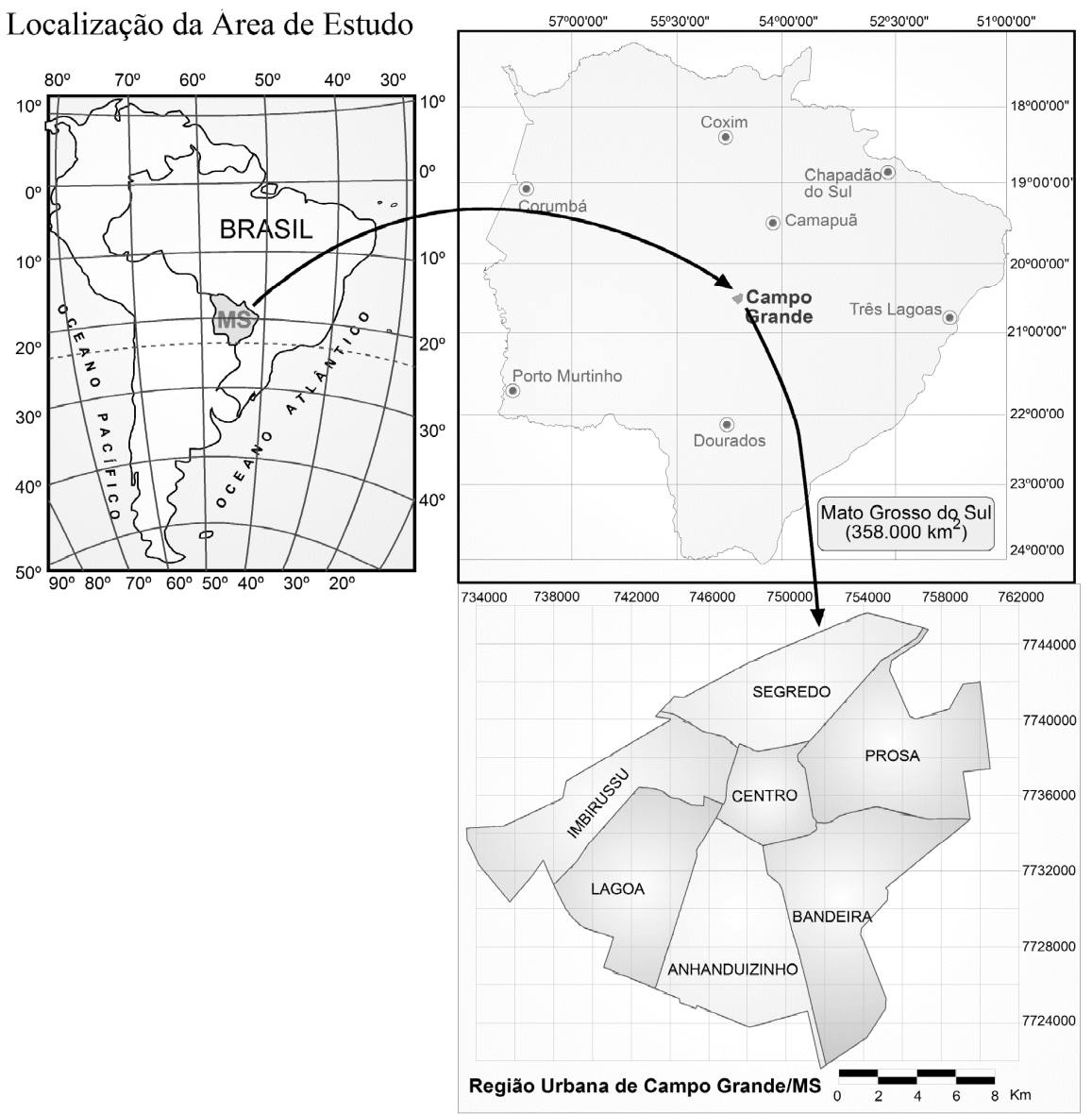

Figura 1 - Mapa de localização da região urbana de Campo Grande-MS, com a delimitação das suas macroregiões

Figure 1 - Location map of the urban area of Campo Grande-MS, with the delimitation of its macro-regions 


\section{ÍNDICES DE INCRUSTAÇÃO E AGRESSIVI- DADE DAS ÁGUAS SUBTERRÂNEAS}

O comportamento agressivo ou incrustante das águas subterrâneas é verificado através da correlação entre o pH medido e o pHe, que é o pH de equilíbrio (LASTORIA, 2002; FEITOSA, 2008). Sua tendência corrosiva/incrustante determina se ocorrerão estas alterações no sistema de explotação e podem ser avaliadas pelo Índice de Saturação de Langelier (LSI - Lagelier Saturation Index) e pelo Índice de Estabilidade de Ryzanr (RSI - Ryznar Stability Index).

Devido às características hidrogeológicas de percolação por meios de porosidade intergranular e fissuras, bem como a capacidade de carrear substâncias desses meios, as águas subterrâneas podem conter diferentes concentrações de sólidos totais dissolvidos, do íon cálcio, e de alcalinidade, que determinam suas propriedades corrosivas ou incrustantes (FEITOSA, 2008).

Apesar da determinação do LSI e RSI em águas subterrâneas ser pouco empregada, muito provavelmente pelo fato de não indicarem a potabilidade destas águas para o consumo humano, esses índices podem nortear os executores dos poços tubulares quanto aos tipos de materiais e equipamentos que devem ser utilizados nessas obras, bem como quanto à frequência e o período de manutenção, visando ao aumento da sua vida-útil. No caso de águas incrustantes, pode ocorrer a redução de sua vazão de explotação; em poços com águas corrosivas, tem se constatado o rompimento do tubo edutor e queda do conjunto moto-bomba, podendo causar a perda do poço devido à inviabilidade de retirada do equipamento. Complementarmente, poderiam ser previstos tratamentos físico-químicos para a inibição das ações corrosivas ou incrustantes ao longo da rede de distribuição de água.

\section{Índice de Saturação de Langelier}

É um modelo de equilíbrio derivado de conceitos teóricos de saturação que indica o grau de saturação do carbonato de cálcio na água, sendo proposto por Langelier no ano de 1946 (FERRAZ, 2007; GRADES, 2004; McNEILL, 2000).

O cálculo é feito tomando-se a diferença entre o $\mathrm{pH}$ medido da água e o pHe (Equação 1), quando esta mesma água apresenta-se saturada com $\mathrm{CaCO}_{3}$ ou em equilíbrio (pHe), parâmetro obtido pela relação entre os coeficientes A, B, C e D (Equação 2), determinados pelas respectivas Equações 3, 4, 5 e 6, sendo a interpretação dos resultados conforme apresentado na Tabela 1.

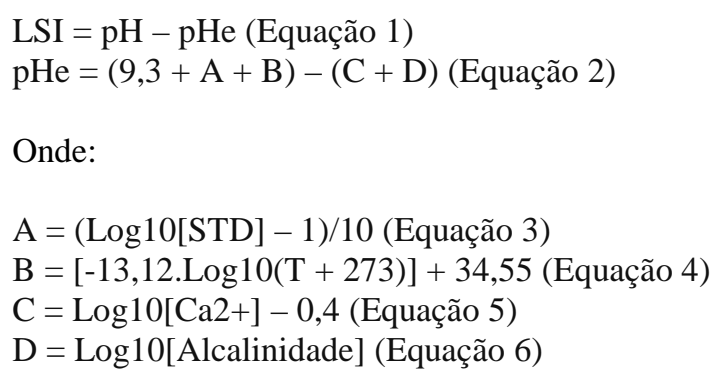

NOTAS: STD $=$ Total de sólidos dissolvidos (mg/L);

$$
\begin{aligned}
& \mathrm{Ca}^{2+}=\text { Concentração de Cálcio; } \\
& \mathrm{T}=\text { Temperatura em }{ }^{\circ} \mathrm{C} .
\end{aligned}
$$

Tabela 1 - Classificação dos valores obtidos com a aplicação do LSI, adaptado de Grades (2004)

Table 1 - Classification of the values obtained using the LSI, adapted from Grades (2004)

\begin{tabular}{cc}
\hline Valor LSI & Indicação \\
\hline$>4$ & Incrustação severa \\
3 a 4 & Incrustação moderada \\
1 a 3 & Incrustação suave \\
0,5 a 1 & Incrustação muito suave \\
$-0,5$ a 0,5 & Balanceado \\
$-0,5$ a -2 & Corrosão suave \\
-2 a -5 & Corrosão moderada \\
$<-5$ & Corrosão severa \\
\hline
\end{tabular}




\section{Índice de Estabilidade de Ryznar}

Proposto em 1944 (FERRAZ, 2007; GRADES, 2004; McNEILL, 2000) aponta para o estado de saturação de carbonato de cálcio, repre- sentado na Equação 7, com interpretação dos resultados conforme apresentado na Tabela 2.

$\mathrm{RSI}=2 \mathrm{pHe}-\mathrm{pH}$ (Equação 7).

Tabela 2 - Classificação dos valores obtidos com a aplicação do RSI, adaptado de Grades (2004)

Table 2 - Classification of the values obtained using the RSI, adapted from Grades (2004)

\begin{tabular}{cc}
\hline Valor RSI & Indicação \\
\hline$>4$ & Incrustação severa \\
4 a 5 & Incrustação forte \\
5 a 6 & Incrustação leve \\
6 a 7 & Balanceado \\
7 a 7,5 & Corrosão moderada \\
7,5 a 9 & Corrosão forte \\
$>9,0$ & Corrosão severa \\
\hline
\end{tabular}

\section{HIDROGEOQUÍMICA}

O município de Campo Grande/MS localizase sobre o afloramento da porção oeste dos derrames, ou trapps, basálticos da Formação Serra Geral, pertencente à Bacia Sedimentar do Rio Paraná, com espessura total variando de 80 a 300 metros na área estudada. As espessuras individuais dos corpos extrusivos variam de 10 até 100 metros e compõem o Sistema Aquífero Serra Geral - SASG (LASTORIA, 2002).

Este sistema aquífero caracteriza-se por ser um aquífero livre, anisotrópico e com porosidade fissural. As estruturas que caracterizam o maciço rochoso são determinadas segundo a morfogênese dos derrames basálticos. Segundo Silva (2007), as principais estruturas encontradas nos derrames basálticos são: contatos interderrames (fendas de grande extensão lateral); zonas de basalto vesicular e amigdaloidal, características de topo de derrame, preenchidas principalmente por calcita, quartzo e zeólitas; áreas de basalto compacto no centro do derrame com poucas fraturas verticais; e a base do derrame, raramente vesicular, com fraturas paralelas ao contato (SILVA, 2007), por onde percolaram soluções hidrotermais, principalmente pelas cavidades de topo e base, precipitando substâncias químicas nas paredes das fraturas ou preenchendo as amígdalas.
Um dos minerais que ocupam as cavidades dos derrames basálticos na região estudada é a calcita $\left(\mathrm{CaCO}_{3}\right)$, a qual apresenta-se usualmente em cris-

tais ou agregados de grânulos finos, ocorrendo como mineral secundário nestas rochas ígneas.

A distribuição petrográfica dos minerais do grupo das zeólitas é restrita e está associada, preferencialmente, às rochas de origem eruptiva e, raramente, formam depósitos minerais economicamente exploráveis (SHINZATO, 2008).

As condições de ocorrência das águas subterrâneas numa região são muito variadas, na medida em que dependem da interação de fatores climáticos, intemperismo e de aspectos geológicos. Tais aspectos determinam a forma de recarga, estocagem, circulação e descarga. Influenciam também na qualidade das águas e determinam as obras de captação, equipamentos de perfuração e as especificações dos materiais que devem ser empregados para o revestimento, filtros, bombas, tubulações entre outros.

Por isso, torna-se necessário o conhecimento da dinâmica das variações faciológicas de cada aquífero, sendo o poder de corrosão/incrustação um dos parâmetros que devem ser analisados no momento da escolha do local onde será realizada a captação de água, para que não ocorram problemas de avarias indesejadas no sistema. 
A classificação hidroquímica permite visualizar a distribuição regional da composição das águas em uma carta temática, que por sua vez pode orientar as autoridades gestoras de recursos hídricos, os perfuradores de poços tubulares e outros profissionais, para identificar aquíferos com melhor qualidade de água, além de permitir uma primeira avaliação da relação entre a mineralogia e a composição da água subterrânea de determinado aquífero (APPELO e POSTMA, 2009).

Segundo Silva (2007), a ocorrência da água subterrânea do SASG está condicionada a fatores genéticos do pacote basáltico (intertraps, amígdalas, vesículas e contatos) e à presença de estruturas (disjunções, fraturas e falhas) que condicionam a circulação das águas nestas rochas. A conexão destes fatores aumenta a capacidade de armazenamento de água.

Lastoria (2002) correlacionou a condutividade elétrica do SASG em Mato Grosso do Sul, verificando o aumento dos sólidos totais dissolvidos (TDS), no sentido do fluxo da água subterrânea nos derrames basálticos. Constatou também que o fluxo é predominantemente em sistemas de diaclasamento horizontal do topo e base dos derrames, em juntas horizontais de grande continuidade, bem como nos planos de contato entre os derrames, não priorizando os modelos tradicionais de circulação de água em rochas fraturadas, que enfatizam as estruturas verticais como principais zonas de circulação e acúmulo de água.

Em Campo Grande, os poços perfurados no Sistema Aquífero Serra Geral, têm profundidade média de $115 \mathrm{~m}$, com vazões variando em torno de $30 \mathrm{~m}^{3} / \mathrm{h}$. O nível estático (NE) e dinâmico (ND) médios são, respectivamente, 20 e 48 metros, e a capacidade específica de $1,07 \mathrm{~m}^{3} / \mathrm{h} . \mathrm{m}$. A oeste da cidade, o fluxo se dá na direção da bacia do rio $\mathrm{Pa}$ raguai, e ao sul, em direção à região central da área de afloramento da Formação Serra Geral em Mato Grosso do Sul, indicando controle estrutural. A área de estudo é considerada uma das duas principais regiões de recarga do SASG no Estado, com afloramento de $40.000 \mathrm{~km}^{2}$. Para toda esta superfície (incluindo dados de poços de Campo Grande), são descritos valores de temperatura da água entre $25 \mathrm{e}$ $28^{\circ} \mathrm{C}, \mathrm{pH}$ variando de 5,5 a $7,8, \mathrm{STD}$ inferior a 300 $\mathrm{mg} / \mathrm{L} ; 84 \%$ das análises indicaram águas agressivas, $11 \%$ em equilíbrio e 5\% incrustantes (LASTORIA, 2002).

A diminuição do $\mathrm{pH}$ das águas subterrâneas está intimamente ligada à dissolução do $\mathrm{CO}_{2}$, infiltrado conjuntamente com água de chuva, que tem como produto o ácido carbônico $\left(\mathrm{H}_{2} \mathrm{CO}_{3}\right)$ que é facilmente ionizável, liberando $\mathrm{H}^{+}$e o íon bicarbonato $\left(\mathrm{HCO}_{3}{ }^{-}\right)$, este com efeito tampão sobre o $\mathrm{pH}$ do meio. A quantidade de $\mathrm{CO}_{2}$ dissolvido na água é que irá definir sua agressividade. A dissolução dos carbonatos é outra reação ácido-base importante, uma vez que o aumento da concentração de $\mathrm{CO}_{3}{ }^{2-}$ promove incremento do $\mathrm{pH}$ e caracteriza a água como incrustante (CUSTÓDIO e LLAMAS, 1983).

Outros problemas de qualidade das águas por corrosão ou incrustação podem ser ocasionados por influencia das condições de bombeamento da água que altera o estado natural de equilíbrio físicoquímico, as alterações produzidas durante a operação e manutenção do poço, a diminuição de recarga no aquífero, devido a impermeabilização do solo e a expansão do cone de rebaixamento atingindo zonas com águas de composição físico-químicas diferentes, como relatado por Tahal/Sanesul (1998).

Também, não menos importante, é a ação humana na alteração do $\mathrm{pH}$ das águas subterrâneas, visto que mudanças de valores de $\mathrm{pH}$ das águas subterrâneas vem sendo observadas em um número crescente de lugares industrializados em todo o mundo (APPELO e POSTMA, 2009; HOUBEN et al., 2009) e até mesmo da temperatura (YALCIN e YETEMEN, 2009), devido a substituição da vegetação por construções e a absorção de energia pelas estruturas urbanas.

\section{MATERIAIS E MÉTODOS}

O estudo foi elaborado em quatro etapas de trabalho, consistindo em uma etapa inicial de pesquisa bibliográfica e levantamento de poços tubulares existentes, uma etapa de campo para coleta de amostras de água, uma etapa laboratorial para realização das análises e a última de tratamento dos dados para interpretação dos resultados.

\section{Levantamento de poços tubulares}

O levantamento de poços tubulares foi realizado, principalmente, no sistema de abastecimento público, sob a concessão da Empresa Águas Guariroba S/A, e, secundariamente, em poços particulares. As informações obtidas para cada poço amostrado foram: localização, nível estático (NE), nível dinâmico (ND), vazão $\left(\mathrm{m}^{3} / \mathrm{h}\right)$, cota altimétrica da boca do poço $(\mathrm{m})$, profundidade $(\mathrm{m})$ e aquíferos contribuintes. Tais dados foram utilizados para a elaboração do mapa potenciométrico do aquífero na área de estudo.

A localização dos poços (Figura 2) foi obtida com auxílio do GPS Garmin eTrex Vista HCx, com coordenadas geográficas dos pontos de explotação na projeção métrica UTM (Universal Transversa de Mercator), datum SAD-69, fuso 21.

\section{Coleta de amostras}

A seleção dos poços tubulares a serem amostrados foi efetuada considerando-se aqueles que 
explotam o SASG, em operação, para o abastecimento público e privado de água. As atividades de campo consistiram basicamente em coleta de amostras e análises físico-químicas, sendo realizadas no período seco, de 14 de junho a 04 de outubro de 2010.

As amostragens foram realizadas no ponto mais próximo da boca do poço, após a eliminação da água contida no edutor, evitando-se a coleta do material presente na tubulação. Para armazenamento das amostras foram utilizados frascos de polietileno transparente, preliminarmente higienizado no laboratório de análises das Águas Guariroba S/A, os quais foram preenchidos até a borda para evitar a ação de diluição de gases na amostra.

Em campo, foram determinadas as temperaturas de cada amostra e do ambiente, e também o $\mathrm{pH}$ com o auxílio de um medidor da marca Hanna, modelo HI8424, bulbo de vidro, o qual era aferido anterior e posteriormente a cada campanha. Após a medição desses parâmetros, as amostras foram lacradas com tampa e acondicionadas em recipiente com isolamento térmico, com refrigeração a gelo à temperatura de $4^{\circ} \mathrm{C}$, para a análise dos parâmetros da Alcalinidade, concentração de cálcio em forma de carbonato e STD em laboratório.

Adicionalmente, foi amostrado material precipitado sobre o conjunto de bombeamento do poço particular 4 (PRT-04), retirado para manutenção, o qual foi submetido à análise por Microscopia Eletrônica de Varredura (MEV) para sua identificação.

\section{Análises laboratoriais}

As amostras de água foram encaminhadas ao Laboratório Operacional da Águas Guariroba S/A localizado na Estação de Tratamento de Água Guariroba - ETA Guariroba, as quais foram analisadas dentro do período de 24 horas.

As análises físico-química de amostras das águas foram efetuadas para os seguintes parâmetros: sólidos totais dissolvidos (STD); concentração de cálcio em forma de carbonato $\left(\mathrm{Ca}^{2+}\right.$ de $\left.\mathrm{CaCO}_{3}\right)$ e alcalinidade em $\mathrm{CaCO}_{3}$.

As metodologias de análise dos parâmetros foram realizadas segundo os procedimentos técnicos definidos pelo Standard Methods for the Examination of Water and Wastewater (APHA, 1992), que consistiram nos métodos analíticos eletrométrico, volumétrico e titulométrico, respectivamente empregados para os parâmetros, STD, Cálcio e Alcalinidade.

\section{Microscopia Eletrônica de Varredura - MEV}

A amostra de material precipitado, coletada no conjunto de bombeamento do poço particular 4, foi analisada por Microscopia Eletrônica de Varredura no Laboratório de Microscopia Eletrônica da UFMS, com imagens de elétrons secundários e retroespalhados. Adicionalmente, foram efetuadas microanálises químicas por espectrometria de raios$\mathrm{X}$ por dispersão de energia (EDS) para a identificação da composição química do mineral precipitado.

\section{Interpretação dos Índices de Langelier (LSI) e Ryznar (RSI)}

De posse dos resultados analíticos físicoquímicos, foram aplicadas as fórmulas dos Índices de Langelier (LSI) e Ryznar (RSI), verificando qual a tendência de comportamento da água subterrânea do SASG em Campo Grande frente ao caráter de corrosão ou incrustação.

Os resultados de cada poço amostrado foram plotados, juntamente com suas respectivas coordenadas geográficas, em ambiente SIG (Sistemas de Informações Geográficas), utilizando-se o software Surfer, para avaliação da distribuição espacial do LSI e RSI, obtendo o mapa de isolinhas da distribuição espacial da tendência de corrosão/incrustação das águas subterrâneas do SASG na Zona Urbana de Campo Grande.

Os resultados dos parâmetros físicoquímicos também foram plotados conforme os índices LSI e RSI, com o intuito de verificar se tais parâmetros acompanhavam a variação desses Índices.

Para auxiliar o entendimento da variação espacial dos índices estudados, comparou-se as distribuições espaciais de corrosão/incrustação das águas subterrâneas com o fluxo subterrâneo no SASG, ou seja, se as substâncias químicas responsáveis por esse caráter estão sendo carreadas de um ponto do aquífero para outro através das interconectividades das fissuras e descontinuidade da Formação Serra Geral.

\section{RESULTADOS E DISCUSSÕES \\ Hidrogeologia do SASG em Campo Grande}

Na Figura 2, é mostrada a localização dos 84 poços tubulares analisados, os quais têm o SASG como principal contribuinte. Deste total, 78 poços são operados pela empresa Águas Guariroba S/A e 6 são poços particulares. As informações hidrogeológicas são apresentadas na Tabela 3. 


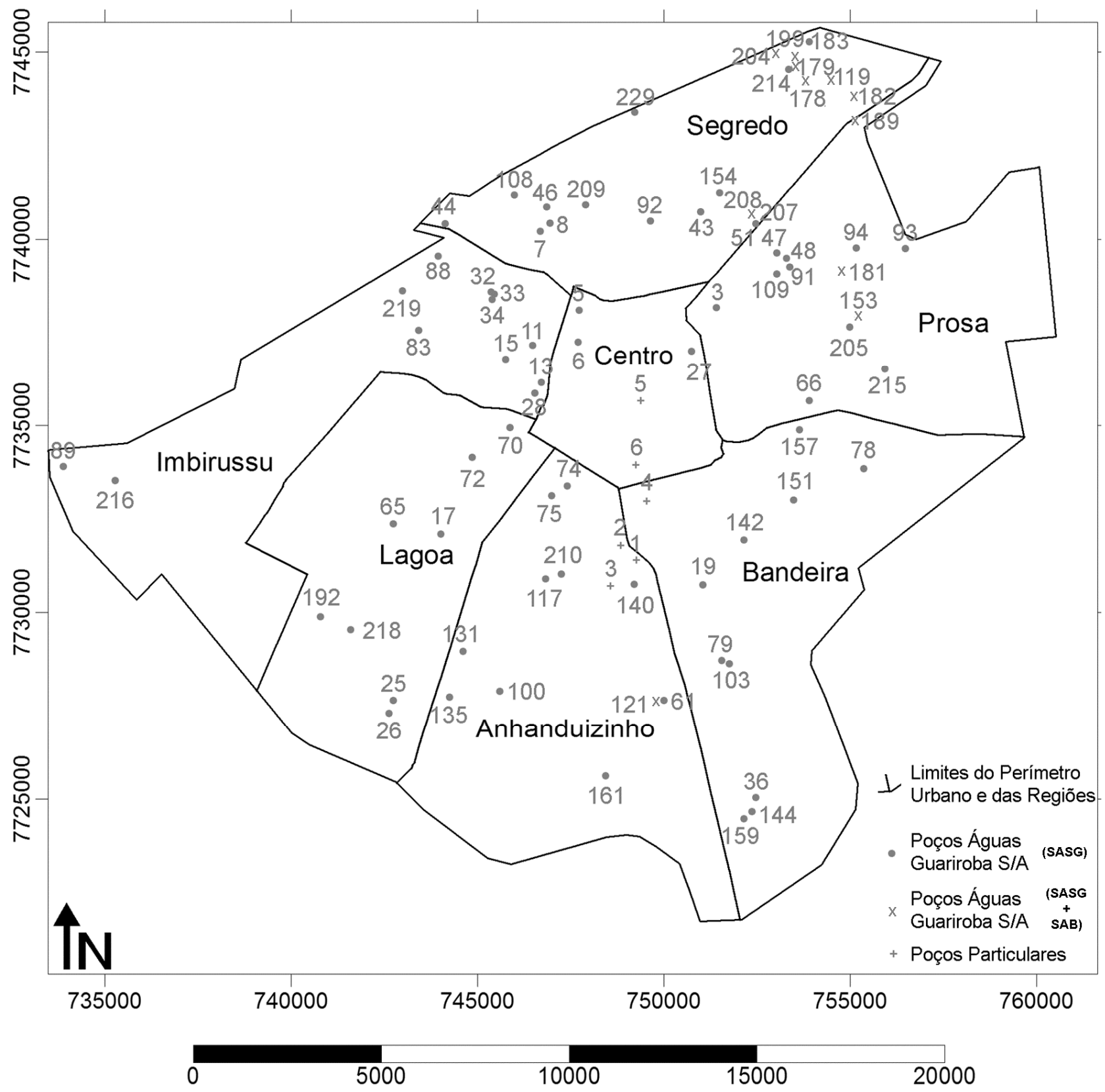

Figura 2 - Localização espacial dos 84 poços tubulares analisados, em Campo Grande, com contribuição do SASG (78 sob concessão da empresa Águas Guariroba S/A e 6 particulares).

Figure 2 - Spatial location of the 84 wells analyzed, which have contribution of SASG, (78 of the company Águas Guariroba S/A and 6 individuals). 
CAVAZZANA,G.H.; LASTORIA, G.; GABAS, S.G.; BEZERRA, C.M. P.

Tabela 3 - Dados hidrodrogeológicos dos poços analisados

Table 3 - Hydrogeologyc data of analyzed wells (continua)

\begin{tabular}{|c|c|c|c|c|c|c|c|c|c|c|c|c|}
\hline Poço & $\begin{array}{l}\text { Cota } \\
\mathrm{NE} \\
(\mathrm{m}) \\
\end{array}$ & $\begin{array}{l}\text { Cota } \\
\text { ND } \\
(\mathrm{m})\end{array}$ & $\begin{array}{c}\mathrm{Q} \\
\left(\mathrm{m}^{3} / \mathrm{h}\right)\end{array}$ & $\begin{array}{l}\text { Prof. } \\
\text { (m) }\end{array}$ & $\begin{array}{c}\text { Temp. } \\
\left({ }^{\circ} \mathrm{C}\right)\end{array}$ & $\mathrm{pH}$ & $\begin{array}{c}\mathrm{Ca} \\
(\mathrm{mg} / \mathrm{L})\end{array}$ & $\begin{array}{c}\text { Alc. } \\
\text { (mg/L) }\end{array}$ & $\begin{array}{c}\text { STD } \\
(\mathrm{mg} / \mathrm{L})\end{array}$ & LSI & RSI & $\begin{array}{l}\text { Aquífe- } \\
\text { ro }\end{array}$ \\
\hline CGR-003 & 615 & 600 & 10.8 & 196 & 25,9 & 6,66 & 13,7 & 22,4 & 98 & -2.4 & 11.5 & SASG \\
\hline CGR-005 & 529 & 516 & 39.3 & 114 & 25,6 & 6,68 & 19,9 & 72,6 & 154 & -1.8 & 10.2 & SASG \\
\hline CGR-006 & 532 & 515 & 41.0 & 111 & 25,7 & 6,52 & 18,7 & 57,0 & 90 & -2.0 & 10.6 & SASG \\
\hline CGR-007 & 587 & 529 & 13.2 & 160 & 25,7 & 6,75 & 31,2 & 64,3 & 192 & -1.6 & 9.9 & SASG \\
\hline CGR-008 & 589 & 569 & 10.8 & 132 & 25,4 & 6,86 & 27,2 & 62,2 & 166 & -1.5 & 9.9 & SASG \\
\hline CGR-011 & 564 & 550 & 27.6 & 99 & 26,1 & 7,30 & 16,3 & 43,2 & 116 & -1.4 & 10.2 & SASG \\
\hline CGR-013 & 562 & 551 & 36.0 & 140 & 26,0 & 7,20 & 18,3 & 49,5 & 118 & -1.4 & 10.1 & SASG \\
\hline CGR-015 & 563 & 543 & 36.6 & 150 & 25,8 & 7,52 & 6,5 & 42,2 & 70 & -1.6 & 10.8 & SASG \\
\hline CGR-017 & 530 & 521 & 18.6 & 150 & 27,0 & 6,63 & 12,0 & 37,0 & 162 & -2.3 & 11.2 & SASG \\
\hline CGR-019 & 567 & 557 & 42.6 & 120 & 25,5 & 6,82 & 22,0 & 63,5 & 92 & -1.6 & 10.1 & SASG \\
\hline CGR-025 & 501 & 490 & 43.8 & 116 & 26,4 & 7,03 & 26,5 & 63,0 & 88 & -1.3 & 9.6 & SASG \\
\hline CGR-026 & 441 & 434 & 18.3 & 95 & 27,1 & 7,63 & 16,0 & 54,0 & 123 & -1.0 & 9.6 & SASG \\
\hline CGR-027 & 590 & 547 & 13.8 & 154 & 26,1 & 6,98 & - & - & - & - & - & SASG \\
\hline CGR-028 & 560 & 546 & 48.0 & 100 & 25,8 & 7,70 & 11,4 & 47,4 & 80 & -1.1 & 10.0 & SASG \\
\hline CGR-032 & 571 & 557 & 12.3 & 100 & 25,5 & 7,31 & 25,7 & 68,5 & 220 & -1.1 & 9.4 & SASG \\
\hline CGR-033 & 572 & 548 & 20.0 & 120 & 25,1 & 7,14 & 20,0 & 70,6 & 145 & -1.3 & 9.8 & SASG \\
\hline CGR-034 & 577 & 555 & 28.4 & 120 & 25,2 & 7,38 & 26,5 & 72,7 & 89 & -0.9 & 9.2 & SASG \\
\hline CGR-036 & 578 & 554 & 13.8 & 150 & 25,9 & 6,40 & 17,0 & 66,0 & 88 & -2.1 & 10.7 & SASG \\
\hline CGR-043 & 581 & 513 & 31.0 & 150 & 25,4 & 7,00 & 24,2 & 43,9 & 111 & -1.6 & 10.1 & SASG \\
\hline CGR-044 & 556 & 548 & 70.0 & 144 & 25,6 & 6,54 & 17,0 & 40,4 & 82 & -2.2 & 10.9 & SASG \\
\hline CGR-046 & 586 & 582 & 7.8 & 145 & 25,4 & 6,75 & 13,8 & 47,7 & 76 & -2.0 & 10.8 & SASG \\
\hline CGR-047 & 635 & 604 & 15.0 & 120 & 25,9 & 7,31 & 16,1 & 45,9 & 117 & -1.4 & 10.1 & SASG \\
\hline CGR-048 & 630 & 589 & 9.0 & 134 & 25,8 & 7,18 & 14,9 & 49,0 & 130 & -1.6 & 10.3 & SASG \\
\hline CGR-051 & 633 & 606 & 42.0 & 100 & 25,9 & 7,21 & 13,7 & 28,6 & 71 & -1.8 & 10.7 & SASG \\
\hline CGR-061 & 511 & 482 & 27.6 & 70 & 25,7 & 6,68 & 16,0 & 48,0 & 89 & -2.0 & 10.7 & SASG \\
\hline CGR-065 & 531 & 516 & 26.0 & 150 & 26,1 & 6,74 & 9,0 & 36,0 & 104 & -2.3 & 11.4 & $\begin{array}{c}\text { SASG / } \\
\text { SAG }\end{array}$ \\
\hline CGR-066 & 612 & 588 & 9.3 & 120 & 26,0 & 7,41 & 14,1 & 35,7 & 82 & -1.5 & 10.3 & SASG \\
\hline CGR-070 & 545 & 510 & 43.2 & 150 & 25,9 & 7,85 & 14,3 & 52,7 & 81 & -0.8 & 9.5 & SASG \\
\hline CGR-072 & 535 & 489 & 21.3 & 150 & 25,4 & 7,17 & 18,3 & 55,9 & 63 & -1.4 & 9.9 & SASG \\
\hline CGR-074 & 511 & 435 & 14.0 & 148 & 26,4 & 6,93 & 20,0 & 55,0 & 146 & -1.6 & 10.2 & SASG \\
\hline CGR-075 & 507 & 489 & 70.8 & 150 & 26,9 & 6,53 & 16,0 & 42,0 & 158 & -2.2 & 11.0 & SASG \\
\hline CGR-078 & 596 & 582 & 37.0 & 120 & 25,2 & 7,22 & 17,0 & 47,9 & 80 & -1.5 & 10.1 & SASG \\
\hline CGR-079 & 547 & 531 & 30.0 & 100 & 25,7 & 6,75 & 51,0 & 69,0 & 107 & -1.3 & 9.3 & $\begin{array}{c}\text { SASG / } \\
\text { SAG }\end{array}$ \\
\hline CGR-083 & 541 & 522 & 30.0 & 120 & 25,5 & 7,82 & 18,3 & 63,0 & 81 & -0.7 & 9.2 & SASG \\
\hline CGR-088 & 536 & 508 & 30.6 & 137 & 25,3 & 7,64 & 17,9 & 53,6 & 78 & -1.0 & 9.6 & SASG \\
\hline CGR-089 & 503 & 489 & 12.6 & 168 & 25,3 & 7,52 & 7,8 & 40,0 & 47 & -1.6 & 10.6 & SASG \\
\hline CGR-091 & 638 & 633 & 15.0 & 168 & 25,9 & 5,23 & 3,2 & 9,2 & 56 & -4.9 & 15.0 & SASG \\
\hline CGR-092 & 562 & 545 & 34.8 & 110 & 25,1 & 7,02 & 17,0 & 27,5 & 87 & -1.9 & 10.8 & SASG \\
\hline CGR-093 & 611 & 595 & 83.0 & 150 & 25,0 & 6,80 & 8,9 & 33,7 & 112 & -2.3 & 11.5 & SASG \\
\hline CGR-094 & 627 & 580 & 13.0 & 150 & 26,0 & 6,86 & 21,7 & 53,0 & 141 & -1.7 & 10.2 & SASG \\
\hline CGR-100 & 484 & 455 & 22.8 & 100 & 27,2 & 8,04 & 16,0 & 47,0 & 60 & -0.6 & 9.3 & SASG \\
\hline CGR-103 & 552 & 545 & 37.5 & 123 & 25,6 & 6,38 & 16,0 & 59,0 & 84 & -2.2 & 10.8 & SASG \\
\hline CGR-108 & 590 & 587 & 24.8 & 120 & 35,3 & 6,62 & 18,7 & 67,4 & 110 & -1.7 & 10.0 & SASG \\
\hline CGR-109 & 622 & 601 & 33.8 & 151 & 25,5 & 7,38 & 14,7 & 72,7 & 147 & -1.2 & 9.8 & SASG \\
\hline CGR-117 & 503 & 478 & 30.0 & 110 & 26,1 & 7,46 & 46,0 & 115,0 & 325 & -0.4 & 8.3 & SASG \\
\hline
\end{tabular}


Tabela 3 - Dados hidrodrogeológicos dos poços analisados

Table 3 - Hydrogeologyc data of analyzed wells (conclusão)

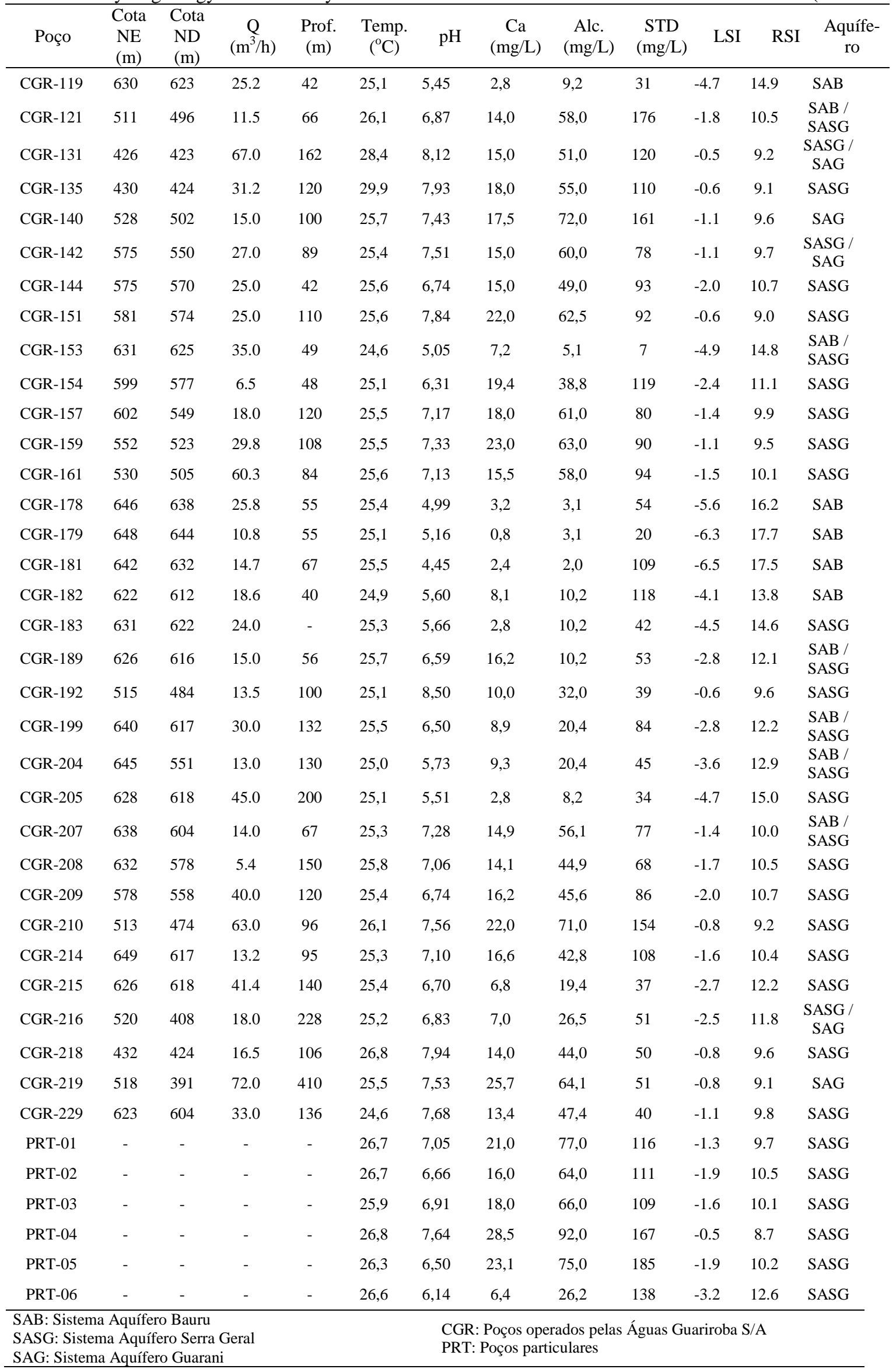


A direção e sentido do fluxo das águas subterrâneas podem ser visualizados no mapa potenciométrico (Figura 3). Neste mapa foi plotada também a hidrografia, com a finalidade de se correlacionar com o padrão de fluxo das águas superficiais.

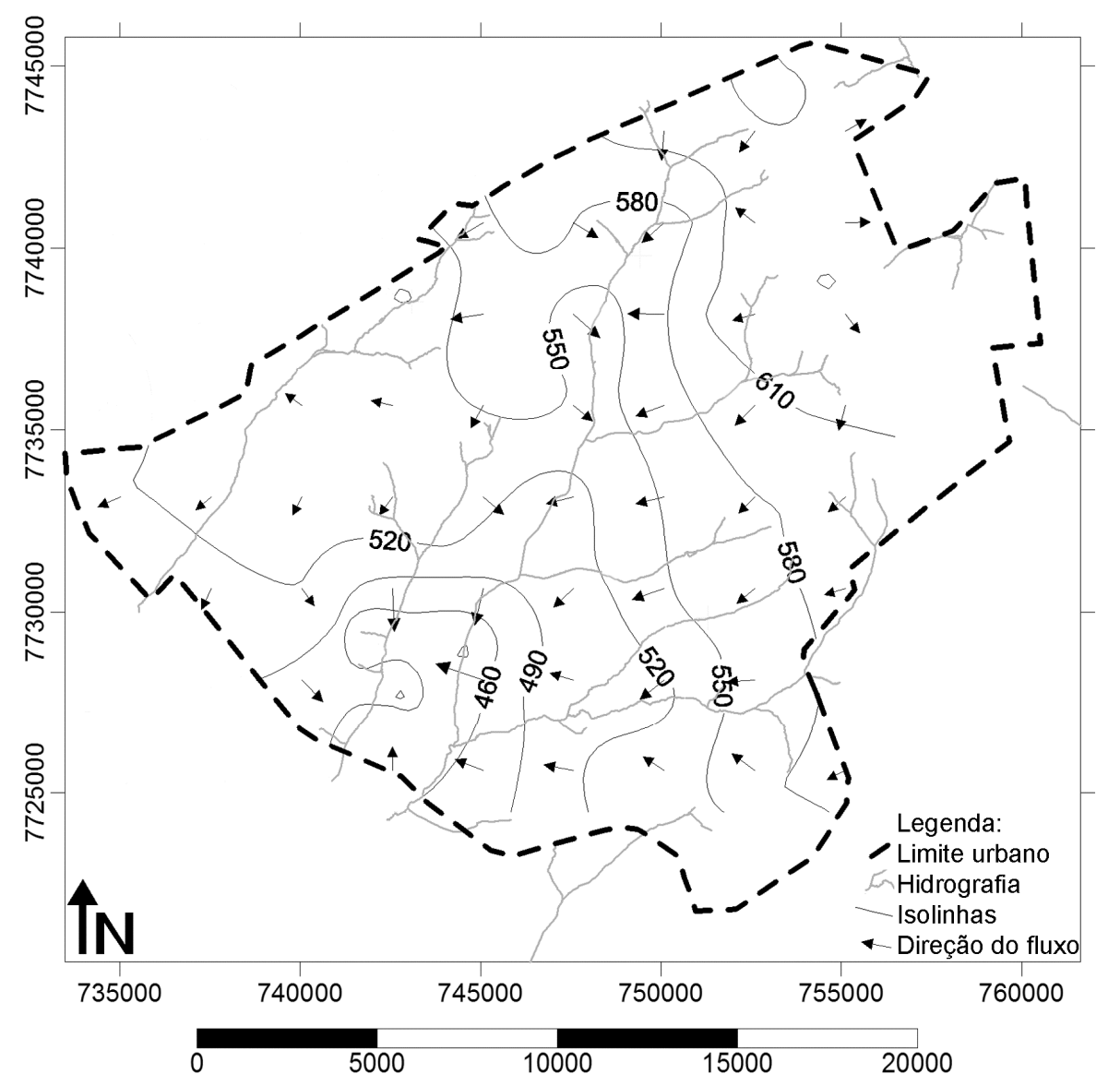

Figura 3 - Mapa potenciométrico com indicação da direção do fluxo das águas subterrâneas do SASG e a hidrografia da região urbana de Campo Grande

Figure 3 - Potentiometric map with direction of groundwater flow and hydrography of the urban are of Campo Grande

Na Figura 3, verifica-se que as linhas equipotenciais do SASG variam de 640 a 430 metros, à NE e SW, respectivamente, acompanhando a hidrografia. O mesmo comportamento é apresentado pela direção do fluxo, predominantemente NE-SW. No quadrante NE da área de estudo, constatou-se um divisor de águas subterrâneas. É importante salientar que nesta região o SASG é recoberto pelo Sistema Aquífero Bauru.

\section{Hidrogeoquímica do SASG em Campo Grande}

A Figura 4 apresenta a variação espacial da alcalinidade (a), da concentração de cálcio (b), do
pH (c), dos Sólidos Totais Dissolvidos (d) e da temperatura da água do SASG (e) na região urbana de Campo Grande. Nota-se que na região NE da área de estudo, encontram-se os menores valores para $\mathrm{pH}$, chegando ao patamar de 4,5, aumentando gradativamente na direção $\mathrm{SW}$, semelhante ao comportamento da direção do fluxo subterrâneo, atingido a casa dos 8,5 (Figura 4 c). Esses valores de pH são próximos aos apresentados por Lastoria (2002), para o Estado de Mato Grosso do Sul, e Silva (2007), para o Estado de Paraná, que determinaram, respectivamente, 4,5 a 7,8 e 5,5 a 6,5 . 
(a)

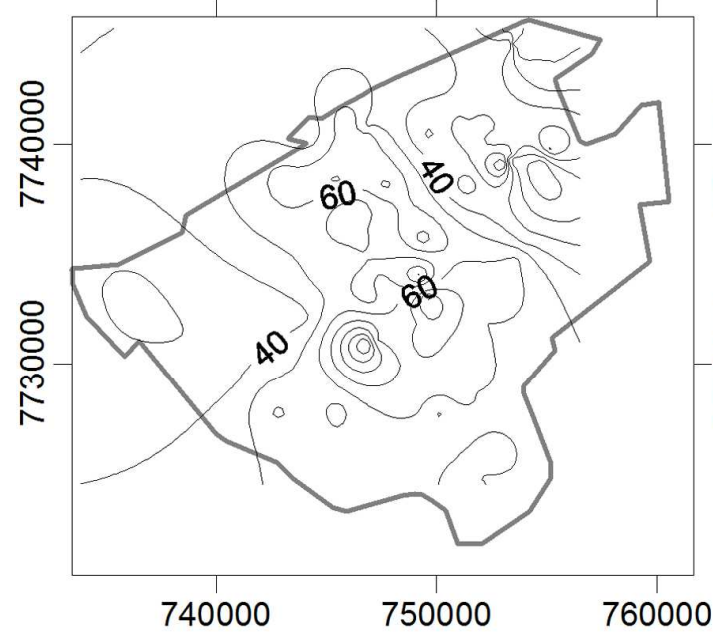

(c)

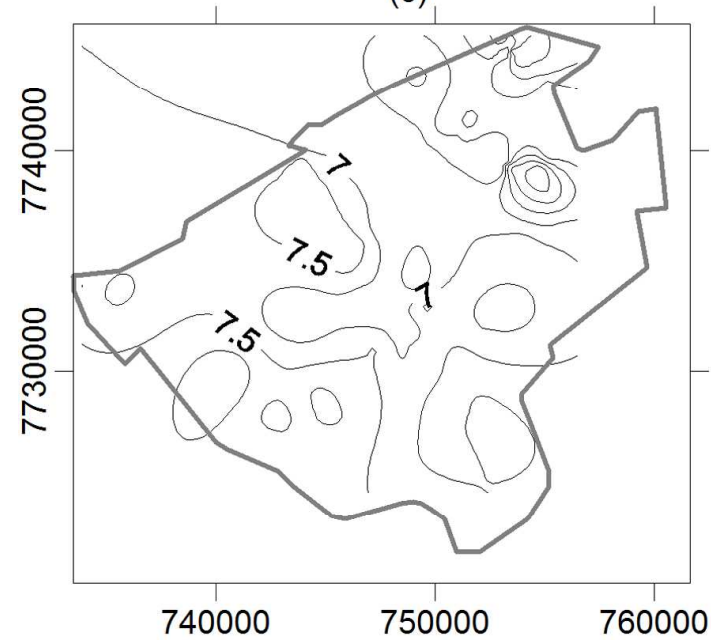

(e)

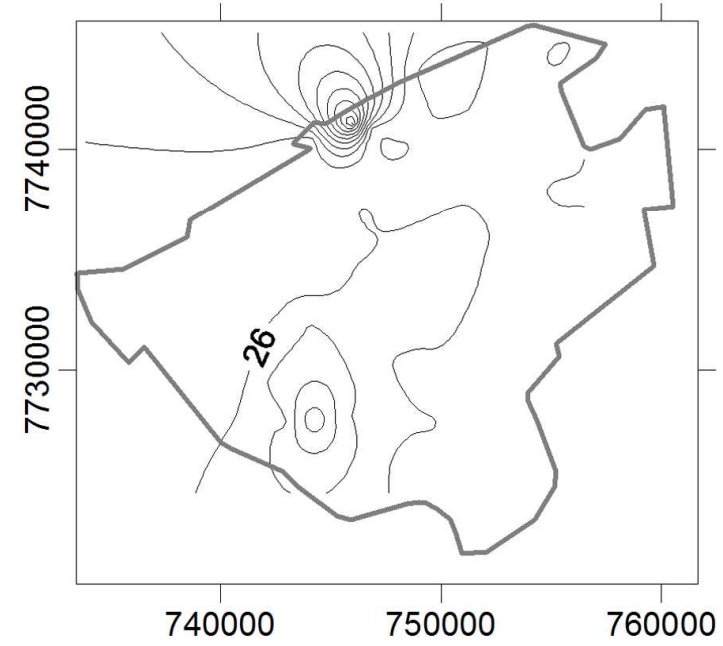

(b)

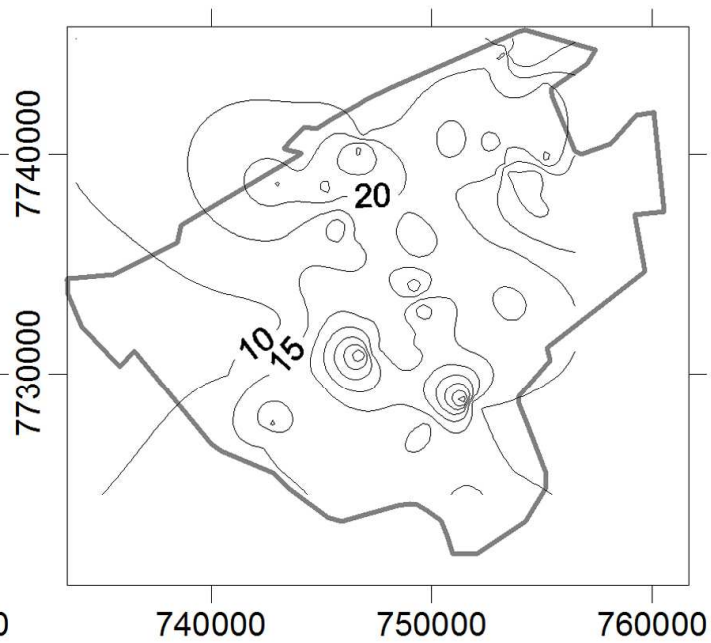

(d)

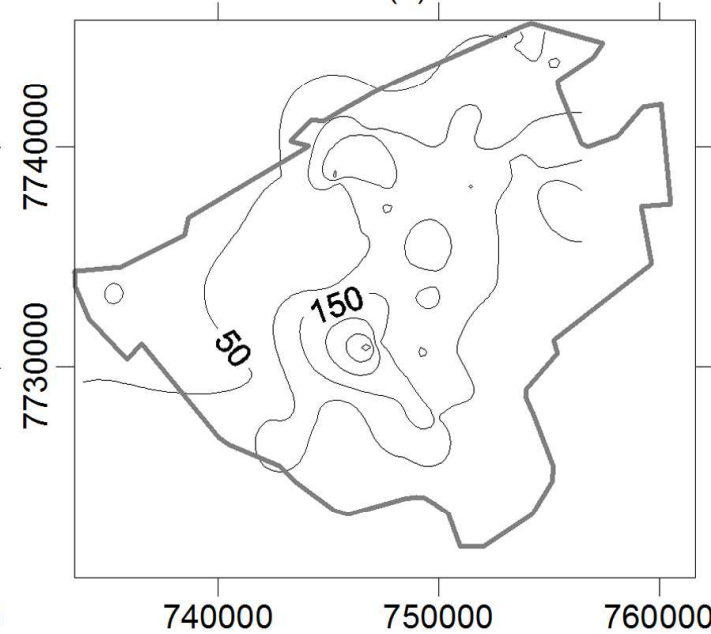

Legenda das variações das isolinhas:

Alcalinidade: $10 \mathrm{mg} / \mathrm{L}$

Cálcio: $5 \mathrm{mg} / \mathrm{L}$

$\mathrm{pH}: 0,5$

Sólidos Totais Dissolvidos: 50mg/L

Temperatura: $10 \mathrm{C}$

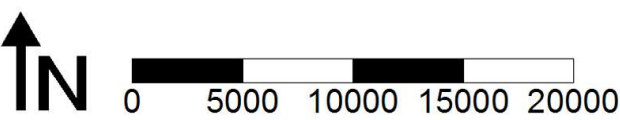

Figura 4 - Distribuição espacial da alcalinidade (a), da concentração de cálcio (b), do pH (c), dos Sólidos To tais Dissolvidos (d) e da temperatura (e) das águas analisadas do SASG na região urbana de Campo Grande.

Figure 4 - Spatial distribution of alkalinity (a), calcium concentration (b), pH (c), Total Dissolved Solids (d) and temperature (e) of the SASG water samples analysis in the urban region of Campo Grande. 
São inúmeros os fatores que contribuem para a variação dos valores de $\mathrm{pH}$ em águas subterrâneas. Os poços com pH baixos (Figura $4 \mathrm{c}$ ) localizam-se na região com a maior altitude da região, confirmada pela presença das nascentes dos córregos e com o nível d'água próximo à superfície, caracterizando, assim, como uma zona de recarga, com presença de águas com baixo tempo de residência e concentrações de $\mathrm{CO}_{2}$ elevadas, devido a sua dissolução na atmosfera e nos solos com presença de matéria orgânica em decomposição. Assim, o dióxido de carbono reage com a água formando ácido carbono que é facilmente ionizável, liberando $\mathrm{H}^{+}$ para o meio acidificando-o, conforme mencionado por Appelo e Postma (2009).

Com o fluxo dessa água ácida pelos interstícios das rochas basálticas, há a dissolução de minerais, inclusive daqueles presentes nas amígdalas das rochas, provocando o aumento de cátions, da alcalinidade e do $\mathrm{pH}$ no sentido do fluxo, proporcionalmente ao tempo de contato água/rocha.

Quanto à variação espacial da temperatura da água (Figura 4 e), destaca-se o norte e o sul da região estudada, atingindo valores na casa dos 35 e $30^{\circ} \mathrm{C}$ respectivamente. Nas demais regiões a temperatura se mantêm aproximadamente em $25^{\circ} \mathrm{C}$.

A região centro-sul da área estudada contém as maiores concentrações dos três parâmetros alcalinidade, concentração de $\mathrm{Ca}^{2+}$ e sólidos totais dissolvidos (STD), (Figura 4).

Para STD, a concentração atinge o pico de $300 \mathrm{mg} / \mathrm{L}$ na região centro-sul da área, diminuindo gradativamente em direção às periferias chegando a concentrações abaixo de 50mg/L (Figura 4 a).

Em relação ao teor de cálcio, que varia de $40 \mathrm{mg} / \mathrm{L}$ até abaixo de $5 \mathrm{mg} / \mathrm{L}$, as concentrações máximas ocorrem na região centro-sul da área de estudo (Figura 4 b). A alcalinidade, com variação de $100 \mathrm{mg} / \mathrm{L}$ até abaixo de 10mg/L (Figura 4 a), apresenta padrão de distribuição compatível com a distribuição de cálcio, como esperado, principalmente o sentido de incremento na direção centro-sul.

Os poços que apresentaram os picos dos parâmetros STD, $\mathrm{Ca}^{2+} \mathrm{e}$ alcalinidade podem estar associados ao potencial de dissolução dos minerais carbonáticos, presentes nas amígdalas descritos por
Lastoria (2002), que por sua vez apresentam distribuição desuniforme, porém em maior concentração em perfis com menores espessuras dos derrames basálticos, tendo em vista sua distribuição preferencial no topo e base dos derrames.

Além disso, como apresentado pelos autores Appelo e Postma (2009), Gonçales e Giampá (2006) e Custódio e Llamas (1983) para a relação entre dissolução e precipitação, águas subterrâneas com

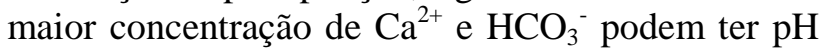
superior a 7,0, como observado nos poços CGR-117 e CGR-210, com potenciais hidrogeniônicos de 7,46 e 7,56, respectivamente.

\section{Potencial de Corrosão e Incrustação do SASG em Campo Grande}

Segundo os resultados obtidos, as águas do SASG explotadas têm características corrosivas. Para o índice LSI, $4 \%$ dos poços possuem água com tendência à corrosão severa, $30 \%$ à corrosão moderada, $65 \%$ à corrosão leve e apenas $1 \%$ balanceado e nenhum poço apresentou características incrustantes. O mesmo ocorreu com o RSI, porém este índice resultou em $98 \%$ de corrosão severa e $2 \%$ de corrosão moderada dos poços analisados.

Tais características foram confirmadas pela Empresa Concessionária, tanto que os poços CGR223,224 e 225 operam com mangueiras de bombeamento ao invés de tubulações de ferro convencional, devido às avarias ocasionadas pela corrosão, inclusive com bombas de aço inoxidável. Também no poço PRT-06, foi relatado que a bomba submersa é trocada a cada ano devido ao ataque químico.

Além disso, os poços com contribuição do Sistema Aquífero Bauru (Formação Caiuá) resultaram em corrosão moderada para severa, em especial quanto ao LSI. Inclusive os três poços com corrosão severa têm como maior contribuinte este Aquífero, sobrejacente ao SASG.

Na Figura 5 e Figura 6 são apresentadas as distribuições espaciais das características agressivas e incrustantes obtidas pela aplicação dos Índices de Ryznar e Langelier, respectivamente. Esses foram correlacionados com o mapa de direção do fluxo subterrâneo e a divisão das macro-regiões da cidade. 


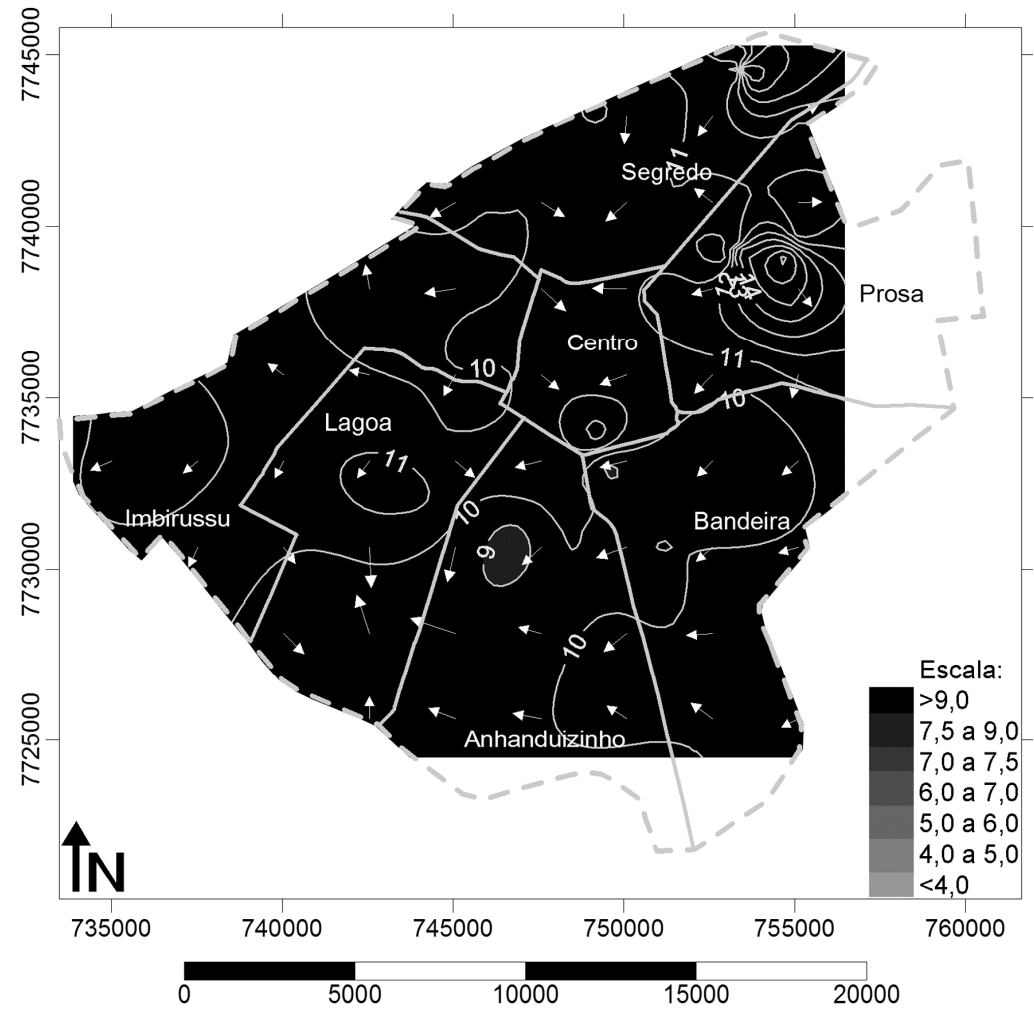

Figura 5 - Distribuição espacial do potencial de corrosão e incrustação, de acordo com o Índice de Estabilidade de Ryznar, para as águas subterrâneas do Sistema Aquífero Serra Geral, na região urbana de Campo Grande.

Figure 5 - Spatial distribution of the potential for corrosion and incrustation, according to the Ryznar Stability Index for the groundwater of the Serra Geral Aquifer System in the urban area of Campo Grande.

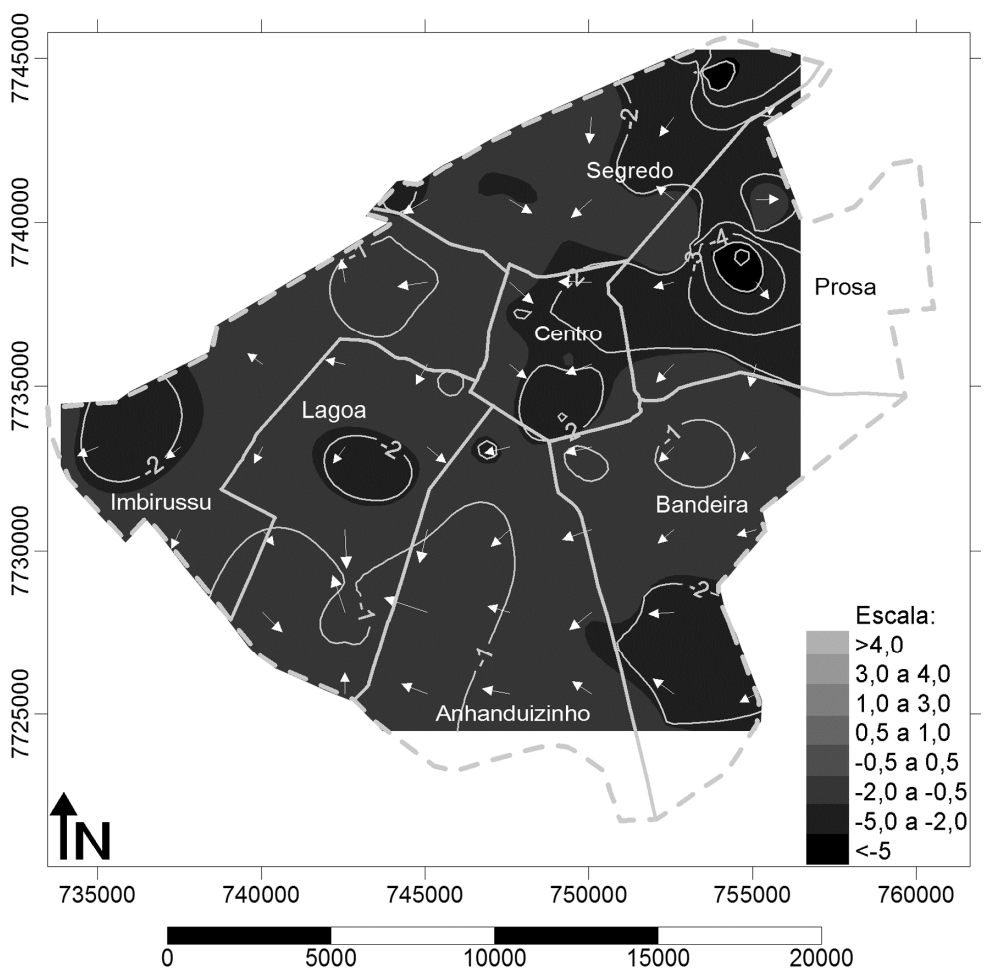

Figura 6 - Distribuição espacial do potencial de corrosão e incrustação, de acordo com o Índice de Saturação de Langelier, para as águas subterrâneas do Sistema Aquífero Serra Geral, na região urbana de Campo Grande.

Figure 6 - Spatial distribution of the potential for corrosion and incrustation, according to the Langelier Saturation Index for the groundwater of the Serra Geral Aquifer System in the urban area of Campo Grande. 
Nota-se que para o RSI, a variação do índice nos poços analisados foi menor em relação ao LSI, cuja amplitude do potencial de corrosão e incrustação atingiu mais intervalos de classes, sendo mais representativo para as características regionais do SASG, na área urbana de Campo Grande.

Apesar disso, a variação dos resultados da aplicação dos dois índices está acompanhando a variação da potenciometria, da direção do fluxo e, principalmente, do $\mathrm{pH}$. Ao norte da macro-região Segredo e no centro da macro-região do Prosa, obtiveram-se valores críticos de corrosão para os índices LSI e RSI, chegando a -6 e a 17 , variando até $-0,5$ e 8,5 , nas respectivas escalas. Mesmo com a larga variação de valores, não foram obtidos resultados de poços incrustantes.

Do ponto de vista hidráulico, a característica predominantemente corrosiva das águas subterrâneas do SASG em Campo Grande, tem propiciado o incremento da vazão específica de poços tubulares que explotam esse Aquífero, em função da dissolução e aumento da porosidade ao longo dos planos de descontinuidades da rocha com o decorrer do tempo de bombeamento desses poços.

\section{Material incrustado}

O material incrustado no conjunto de bombeamento do poço particular 4 e analisado por microscopia eletrônica de varredura trata-se do argilomineral caulinita, como indicado pelo seu hábito cristalino (Figura a) e sua composição química (Figura b). A caulinita foi identificada por Lastoria (2002) como um dos minerais que preenchem fraturas secundárias do basalto, assim como é comum o preenchimento de vesículas da rocha basáltica por calcita. Contudo, em tubulação de adutora de poço tubular perfurado no SASG na cidade de Paranaíba (MS) ocorreu incrustação por aragonita.

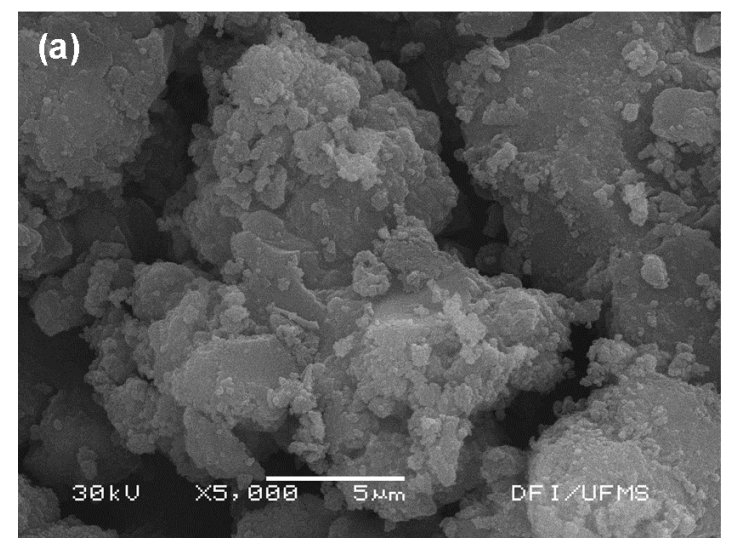

(b)

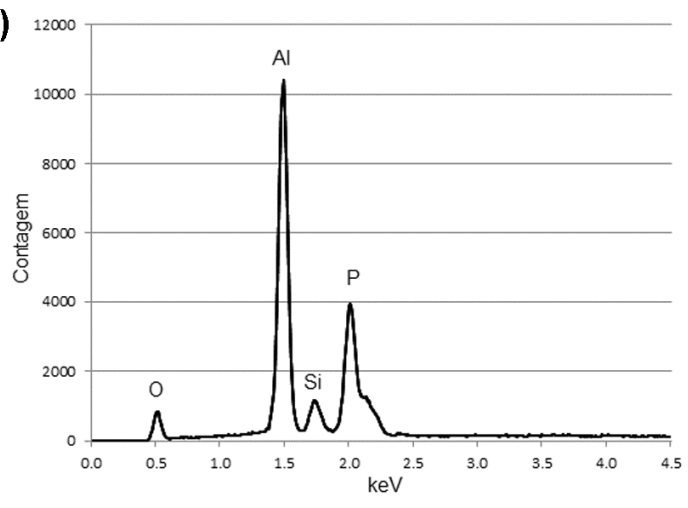

Figura 7 - Imagem de elétrons secundários de microscópio eletrônico de varredura (MEV) (a) e gráfico de espectrometria de raios-X por dispersão de energia (EDS) (b) do material coletado no equipamento do poço particular 4.

Figure 7- Secondary electrons image from scanning electronic microscope (SEM) (a) and X-ray spectrometry of energy dispersion (EDS) (b) of the material collected from the equipment of the private well number 4.

\section{CONCLUSÕES}

Tomando-se por base os resultados obtidos, pode-se concluir que as águas do Sistema Aquífero Serra Geral, explotadas na região urbana do município de Campo Grande, são agressivas, pois $99 \%$ das amostras resultaram em corrosividade, e dessas, $64 \%$ estão na categoria de corrosão leve, para o Índice de Saturação de Langelier, e $98 \%$ dos poços têm água classificada como corrosiva severa, segundo o Índice de Estabilidade de Ryznar.

Com base frequência de manutenção nos equipamentos devido a problemas de agressividade, relatados pelo sistema operacional da Concessionária Águas Guariroba S/A, considera-se que o LSI é o índice mais apropriado para a avaliação deste parâmetro.
A variação dos índices está intrinsecamente relacionada com a direção e sentido do fluxo e, principalmente, mudança do $\mathrm{pH}$.

Os poços com maior potencial de corrosão são os que recebem contribuição do Sistema Aquífero Bauru (Formação Caiuá), podendo-se afirmar que tal Aquífero, formado por sedimentos continentais cretáceos, contribui também para o comportamento corrosivo das águas subterrâneas na região estudada.

Conclui-se também que a recarga do SASG na região $\mathrm{NE}$ da área estudada é responsável pelas altas concentrações de $\mathrm{CO}_{2}$ dissolvido e que, durante seu fluxo para SW, ocorre a dissolução ou a lixiviação dos minerais presentes nas descontinuidades das rochas, acarretando o aumento do $\mathrm{pH}$ da água. 
O comportamento corrosivo da água subterrânea pode justificar a baixa incidência de mineraisdepositados nas tubulações e equipamentos.
A caulinita presente nas descontinuidades das rochas pode ser lixiviada pelo fluxo subterrâneo e incrustado nas tubulações e equipamentos, como observado no poço particular 4 (PRT-04).

\section{AGRADECIMENTOS}

À Coordenação de Aperfeiçoamento de Pessoal de Nível Superior - CAPES pelo apoio financeiro. À Águas Guariroba S/A por possibilitar a coleta de amostras nos poços sob sua operação, pela realização das análises laboratoriais e, em especial, pelas participações dos profissionais Clayton Bezerra, Vera Lucia Sandim e Lilliane Maia Tcacenco. Ao Químico Geraldo Paes por possibilitar a coleta do material incrustado. Ao Físico Luiz Felipe Placa do Laboratório de Microscopia Eletrônica de Varredura do CCET/UFMS.

\section{REFERÊNCIAS}

APHA, AWWA, WEF. standard methods for the examination of water and wastewater. $18^{\text {th }}$ ed., Washington: American Public Health Association, 1992.

APPELO, C.A.J.; POSTMA, D. Geochemistry, groundwater anda pollution. 2.ed. $4^{\text {th }}$ corrected reprint. Amsterdam: A.A. Balkema Publisher, 2009.

BRASIL. IBGE - INSTITUTO BRASILEIRO DE GEOGRAFIA E ESTATÍSTICA. Censo demográfico 2010. Brasília, 2010 .

CAMPO GRANDE, MATO GROSSO DO SUL. Lei Complementar $n^{\circ} \mathbf{7 4}$, de 06 de setembro de 2005 . Dispõe sobre o ordenamento do uso e da ocupação do solo no município de Campo Grande, e dá outras providências. Campo Grande, 2005.

CUSTÓDIO, E.; LLAMAS, M. R. Hidrologia subterrânea. Barcelona: Omega, 1983.

FEITOSA, F.A.C.. Hidrogeologia: conceitos e aplicações. 3. ed. rev. e ampl. - Rio de Janeiro: CPRM: LABHID, 2008. 812p.

FERRAZ, R. de C. Avaliação de sistema alternativo de proteção contra a corrosão em circuito de água de refrigeração. Dissertação (Mestrado em Ciências em Engenharia Metalúrigca e de Materiais). Instituto Alberto Luiz Coimbra de Pósgraduação e Pesquisa de Engenharia, Universidade Federal do Rio de Janeiro. Rio de Janeiro, 2007. 92p.

FOSTER, S. D.; HIRATA, R.; HOWARD, K.W.F. Groundwater use in developing cities: policy issues arising from current trends. Hydrogeology Journal , v.19, p. 271-274, 2011.

GONÇALES, V.G.; GIAMPÁ, C.E.Q. (Ed.) Águas subterrâneas e poços tubulares profundos. São Paulo: Signus Editora, 2006.

GRADES, E. des A. Modelling and simulation of $\mathrm{CO}_{2}$ release in multiple-effect distillers for seawater desalination. jordanien, 2004. p 78-84. Dissertation (Doktor-Ingenieur). Mathematisch-Naturwissenschaftlich-Technische Fakultät der Martin-Luther-Universität Halle-Wittenberg in Tafilah.
HOUBEN, G.; TUNNERMEIER, T.; EGRAR, N.; HIMMELSBACH, T. Hydrogeology of the Kabul Basin (Afghanistan), part II: groundwater geochemistry. Hydrogeology Journal 17: p.935-948, 2009.

LASTORIA, G. Hidrogeologia da formação serra geral no Estado de Mato Grosso do Sul. Tese (Doutorado em Geociências). Instituto de Geociências e Ciências Exatas, Universidade Estadual Paulista. Rio Claro, 2002. 133p.

McNEILL, L. S. Water quality factors influencing iron and lead corrosion in drinking water. Dissertation (Doctor Degree in Civil and Environmental Engineering). Faculty of the Virginia Polytechnic Institute and State University. Blacksburg, VA, USA, 2000. p 1-12.

SECRETARIA DE ESTADO DE MEIO AMBIENTE, DO PLANEJAMENTO, DA CIÊNCIA E TECNOLOGIA E INSTITUTO DE MEIO AMBIENTE DE MATO GROSSO DO SULSEMAC. Plano Estadual de recursos hídricos Estado de Mato Grosso do Sul. Campo Grande/MS: Editora UEMS, 2010.

SILVA, A. de B. e. Conectividade e compartimentação magnética-estrutural dos Sistemas Aquíferos Serra Geral e Guarani na região central do Estado do Paraná. Curitiba, 2007. 182p. Dissertação (Mestrado em Geologia Ambiental). Setor de Ciências da Terra, Universidade Federal do Paraná.

SHINZATO, M.C.; MONTANHEIRO, T.J. JANASI, V. de A.; NEGRI, F. de A.; YAMAMOTO, J.K.; ANDRADE, S. Caracterização tecnológica das zeólitas naturais associadas às rochas eruptivas da Formação Serra Geral, na região de PirajuOurinhos (SP). Revista Brasileira de Geociências, v.38, n.3, p. 524-532, 2008.

TAHAL CONSULTING ENGINEERS LTD e EMPRESA DE SANEAMENTO DE MATO GROSSO DO SUL S. A. - SANESUL. Relatório final: Estudos Hidrogeológicos de Mato Grosso do Sul. 736p. Campo Grande, 1998.

YALCIN, T.; YETEMEN, O. Local warming of groundwaters caused by the urban heat island effect in Istanbul, Turkey. Hydrogeology Journal, v.17: p.1247-1255, 2009. 